\title{
Selective surgical management of neural tube malformations
}

\author{
R C EVANS, B TEW, M D THOMAS, AND J FORD \\ Department of Child Health, University of Wales College of Medicine, and Spina Bifida Unit, \\ Cardiff Royal Infirmary
}

SUMMARY The physical characteristics of 49 children with spina bifida cystica, survivors of a group subjected to selection for early surgery are compared with 39 children alive from an earlier unselected series, born in the 1960s, and reviewed retrospectively. Sixteen children were also studied in whom the initial decision not to operate had been followed by survival and subsequent treatment.

Children selected for initial surgery have a significantly lower mortality than those not selected and their mobility at 5 to 7 years of age is better, although only marginally so compared with the unselected group. Selection does not decrease the need for shunt treatment of the associated hydrocephalus.

None of those not initially selected for surgery have normal faecal or urinary continence, whereas $35 \%$ of the selected in group have normal continence and urinary tracts.

Children treated immediately have significantly higher degrees of intelligence than both the unselectively treated and those whose treatment was delayed but a fifth of the latter group were intellectually normal. There were only small differences in intelligence between children given delayed treatment and those unselectively treated, suggesting that postponing surgery does not necessarily have a deleterious effect on ability.

In the early 1970 s we formulated criteria for early closure of the spinal lesion in spina bifida cystica based on Lorber's observations ${ }^{1}$ and Shurtleff's policy in Seattle (Shurtleff DB, personal communication). The impact of this policy was'seen by 1973 when the proportion of referred patients receiving immediate surgery fell to $60 \%$. After reports assessing the physical and intellectual status of patients since selection has become an accepted part of management of this condition, ${ }^{23}$ we decided to review survivors subject to selection and compare their physical and psychological characteristics with the survivors of an unselected series born between 1964 and 1966 who are still under our care in the South Wales Spina Bifida Unit in Cardiff.

\section{Method}

During the period under review (January 1973 to December 1978) 119 patients were referred to our unit, 65 of whom were submitted for immediate surgery. Forty nine $(75 \%)$ of these children treated surgically survived to follow up: these are known as the 'selected in' group. Also available for study were 16 patients known as the 'selected out' group, nine $(16 \%)$ of whom were survivors of the original 54 patients who were not surgically treated at first. These patients were excluded if one or more of the following adverse criteria were present: (1) neurological level proximal to $\mathrm{L}_{2}$ indicated by paralysis of all leg movements apart from hip flexion; (2) head circumference $2 \mathrm{~cm}$ or more above the 98th centile for gestational age; (3) other severe congenital abnormalities or gross spinal or limb deformities; and (4) severe birth asphyxia, cerebral haemorrhage, or prematurity. In general, social considerations such as large family size or illegitimacy were not considered sufficient grounds for exclusion from early treatment if no other adverse criteria were present. During the years under scrutiny, paediatricians at district general hospitals in the catchment area became increasingly confident in making decisions regarding early management, and as a result a further group of seven patients were available for study who had been initially excluded by our colleagues but referred for treatment when they 
showed a will to live. These are included in the selected out group.

From 1976 we noted a considerable decrease in referrals to our unit (Figure) associated with an apparent natural decline in incidence of the disease coupled with a falling birth rate and the introduction of antenatal screening and selective termination. ${ }^{45}$ Thirty nine of the 121 patients born during the years 1964 to 1966, who were unselectively treated in our unit and still under our care, formed a comparison group. At 5 years of age the survival rates for these children was $46 \%$ which fell to $44 \%$ living at 7 years.

It was possible to make retrospective assessment of their physical status from the records. Their performance on intelligence and attainment tests had previously been collected when they were 5 and 7 years old. ${ }^{6}$

\section{Results}

Mortality. There was a highly significant difference between the mortality rates of patients meeting the selection criteria and those selected out because of adverse conditions $\left(\chi^{2}=38.4, \mathrm{P}<0.001\right)$. The proportion of meningocele and encephalocele patients was not significantly different in the unselected and selected in groups but all the survivors in the selected out group had myelomeningoceles (Table 1). Selection criteria are well described for myelomeningocele but the management of patients with encephalocele is still subject to much discussion. ${ }^{8}$ The association of the latter lesion with appreciable microcephaly, that is head circumference $2 \mathrm{~cm}$ or less than the 2 nd centile for gestational age, was regarded by us as an adverse criterion and two patients were excluded for this reason; but in

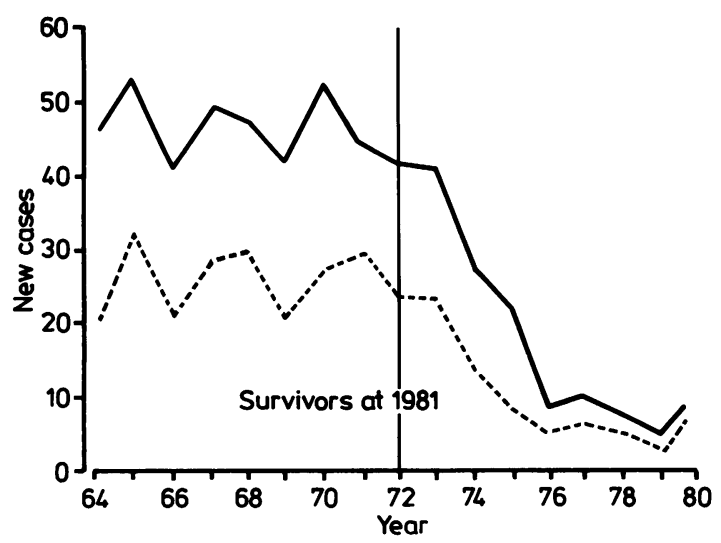

Figure Number of referrals and survivors South Wales Spina Bifida Unit 1964-80.
Table 1 Type of lesion in children subjected to selection for early surgery (selected in and selected out groups) and those from an unselected group

\begin{tabular}{lccc}
\hline & $\begin{array}{l}\text { Unselected } \\
\text { No (\%) }\end{array}$ & $\begin{array}{l}\text { Selected in } \\
\text { No (\%) }\end{array}$ & $\begin{array}{l}\text { Selected out } \\
\text { No (\%) }\end{array}$ \\
\hline $\begin{array}{l}\text { Meningocele } \\
\text { Myelomeningocele }\end{array}$ & $6(15)$ & $8(16)$ & 0 \\
Encephalocele & $30(77)$ & $37(76)$ & $16(100)$ \\
Total & $3(8)$ & $4(8)$ & 0 \\
\hline
\end{tabular}

general children with encephalocele without severe defects were subjected to surgery.

Level of lesion. As would be anticipated, $89 \%$ of those selected in for surgery had lesions below $\mathrm{L}_{2}$ (Table 2). Four patients (11\%) had lesions above $\mathrm{L}_{2}$ but were treated with initial surgery for back closure either at the parents' request or if the attending medical staff felt there was some doubt about the situation in so far as no other adverse factors were present. Thirteen of the sixteen $(81 \%)$ denied immediate closure had lesions above $\mathrm{L}_{2}$ neurologically and were significantly different $\left(\chi^{2}=27 \cdot 5\right.$, $P<0.001)$ from those selected in. The three patients with lesions below $L_{3}$ were excluded from immediate treatment either because of severe hydrocephalus at birth, other adverse criteria, or at the parents' request. Eight of the $30(27 \%)$ in the unselected group had lesions above $\mathrm{L}_{2}$ compared with four of the $37(11 \%)$ of the selected group. These proportions were not significantly different $\left(\chi^{2}=3 \cdot 09, \mathrm{P}=0 \cdot 30\right)$.

Hydrocephalus and shunt insertion. Our study shows that the policy of selection does not necessarily reduce the number of patients requiring valve insertion, for $54 \%$ of the unselected and $51 \%$ of the selected group were surgically treated (Table 3). A higher number showing clinical spontaneous arrest of the hydrocephalus is seen in the selected in group. Among survivors of both policies, 30 to $40 \%$ do not have severe hydrocephalus, but 14 of the $16(88 \%)$ of the survivors initially selected out have shunts.

Table 2 Level of lesion (myelomeningoceles only) in the three patient groups

\begin{tabular}{lccc}
\hline & $\begin{array}{l}\text { Unselected } \\
\text { No (\%) }\end{array}$ & $\begin{array}{l}\text { Selected in } \\
\text { No (\%) }\end{array}$ & $\begin{array}{l}\text { Selected out } \\
\text { No (\%) }\end{array}$ \\
\hline Above $\mathrm{L}_{2}$ & $8(27)$ & $4(11)$ & $13(81)$ \\
$\overline{\mathbf{L}}_{2}-\overline{\mathbf{S}}_{1}$ & $19(63)$ & $30(81)$ & $3(19)$ \\
$\mathbf{S}_{2}-\mathrm{S}_{5}$ & $3(10)$ & $3(8)$ & 0 \\
Total & 30 & 37 & 16 \\
\hline
\end{tabular}


Table 3 Hydrocephalus in the three patient groups

\begin{tabular}{lccc}
\hline & $\begin{array}{l}\text { Unselected } \\
\text { No (\%) }\end{array}$ & $\begin{array}{l}\text { Selected in } \\
\text { No (\%) }\end{array}$ & $\begin{array}{l}\text { Selected out } \\
\text { No (\%) }\end{array}$ \\
\hline Shunted & $21(54)$ & $25(51)$ & $14(88)$ \\
Arrest & $2(5)$ & $8(16)$ & $1(6)$ \\
None & $16(41)$ & $16(33)$ & $1(6)$ \\
Total & 39 & 49 & 16 \\
\hline
\end{tabular}

The percentage requiring shunts in the selected in group $(51 \%)$ is higher than that found among the Sheffield series ${ }^{2}$ and probably reflects differences in management. In the latter series, isosorbide was often used to reduce intracranial pressure, but we have not found this treatment successful in treating hydrocephalus and thus more of our patients have been surgically treated. Selection has an insignificant effect upon the need for subsequent valve revisions for $62 \%$ of shunts in the unselected group were revised compared with $56 \%$ in the selected in group.

In the unselected group the median age for shunt insertion was $7 \cdot 3$ weeks, and $90 \%$ had a valve by 6 months of age. With selection there was a tendency towards earlier surgery, the median age falling to 5 weeks, with $92 \%$ treated by 18 weeks, and all by 20 weeks. The hydrocephalus was treated without undue delay in the survivors of the selected out group, the median age for insertion of a shunt being 8 weeks. The earliest shunt was inserted at 2 weeks of age; $93 \%$ had valves by 6 months, and all by 7 months.

Mobility. Selection seems to improve mobility as might be anticipated from the use of a neurological level of the lesion as a criterion for inclusion within a treatment group. Almost half of the group selected in for treatment at birth, have either normal or only slightly impaired movement compared with nearly one third of the unselected series (Table 4). These proportions were just significantly different $(P=0 \cdot 05)$. Assessment of mobility in those initially selected out showed that five of the $16(31 \%)$ were completely chairbound and the remainder dependent on aids.

Table 4 Mobility in the three patient groups

\begin{tabular}{lccc}
\hline & $\begin{array}{l}\text { Unselected } \\
\text { No (\%) }\end{array}$ & $\begin{array}{l}\text { Selected in } \\
\text { No (\%) }\end{array}$ & $\begin{array}{l}\text { Selected out } \\
\text { No (\%) }\end{array}$ \\
\hline Unimpaired & $6(15)$ & $14(29)$ & 0 \\
Slight Impairment & $7(18)$ & $9(18)$ & 0 \\
Aids & $6(15)$ & $5(10)$ & 0 \\
Aids/chair & $12(30)$ & $18(37)$ & $11(69)$ \\
Chair bound & $8(20)$ & $3(6)$ & $5(31)$ \\
Total & 39 & 49 & 16 \\
\hline
\end{tabular}

Both of these proportions were significantly poorer $\left(\chi^{2}=19.4, P<0.001\right)$ than the selected in sample. The degree of impaired mobility was closely related to the need for orthopaedic and physiotherapy care and support.

Urinary and faecal incontinence. None of the selected out patients had normal urinary continence and most were managed using napkins. Just over a third $(35 \%)$ of the selected in group have normal urinary continence and a normal urinary tract (Table 5). This is somewhat lower than the figure of $55 \%$ quoted by Lorber and Salfield. ${ }^{2}$ Most $(46 \%)$ of the selected in group are still in napkins for some are presently too young to be trained to catheterise themselves or use a penile collecting device, but in due course they should be able to achieve reliable social control with these procedures. An interesting observation is the reduction in the number in the unselected series who had urinary diversions $(37 \%)$ compared with only one child $(2 \%)$ in the selected in group. This reflects the present policy of reserving this operation for patients in whom there is evidence of upper renal tract deterioration due to outlet obstruction despite surgery to the bladder neck to relieve this. Diversion operations are no longer performed merely to achieve social continence in the absence of renal pathology. Among the selected out group, none have faecal continence and all either soil or require regular medication or manual evacuation, or both. In contrast, just over half of both the selected and unselected groups have normal continence or regular bowel function without the use of suppositories (Table 6).

Epilepsy. Up to one third of children with spina bifida and hydrocephalus are liable to seizures, ${ }^{9}$ but this study showed that appreciably lower proportions of children in each group had this complication. Further, there seemed to be little difference between the groups, with seizures occurring in $8.0 \%$ of the unselected group, in $4 \%$ of the selected in group, and in $6 \%$ of the selected out group. This

Table 5 Urinary continence in the three patient groups

\begin{tabular}{lccc}
\hline & $\begin{array}{l}\text { Unselected } \\
\text { No (\%) }\end{array}$ & $\begin{array}{l}\text { Selected in } \\
\text { No }(\%)\end{array}$ & $\begin{array}{l}\text { Selected out } \\
\text { No }(\%)\end{array}$ \\
\hline Normal & $9(24)$ & $17(35)$ & 0 \\
Napkins & $15(40)$ & $22(46)$ & $11(69)$ \\
Catheterisation & 0 & $5(10)$ & $2(13)$ \\
Diversion & $14(37)$ & $1(2)$ & $2(13)$ \\
Penile appliance & 0 & $3(6)$ & $1(6)$ \\
Total & $38^{*}$ & $48^{*}$ & 16 \\
\hline
\end{tabular}

*Data on one subject missing. 
Table 6 Faecal continence in the three patient groups

\begin{tabular}{lccc}
\hline & $\begin{array}{l}\text { Unselected } \\
\text { No (\%) }\end{array}$ & $\begin{array}{l}\text { Selected in } \\
\text { No }(\%)\end{array}$ & $\begin{array}{l}\text { Selected out } \\
\text { No (\%) }\end{array}$ \\
\hline $\begin{array}{l}\text { Normal } \\
\text { Regular toiletting }\end{array}$ & $11(29)$ & $18(38)$ & 0 \\
$\begin{array}{l}\text { Suppositories/manual } \\
\text { evacuation }\end{array}$ & $9(24)$ & $9(18)$ & 0 \\
Soils & $13(34)$ & $14(29)$ & $14(88)$ \\
Total & $5(13)$ & $7(15)$ & $2(12)$ \\
\hline
\end{tabular}

*Data on one subject missing.

latter figure is of particular interest considering the high proportion $(87 \%)$ of this group who had valve dependant hydrocephalus, known to be associated with higher rates of epilepsy.

Upper limb function. Fifty per cent of the selected in sample seemed to have normal upper limb function on clinical examination, with no clear physical signs indicative of abnormality. On three tasks taken from the test of motor impairment, however, the selected in patients were significantly slower on right handed tasks $(\mathrm{P}<0.001)$ than they were using their left or both hands $(\mathrm{P}<0.05)$ in comparison with 56 non-handicapped controls, matched for sex and age attending ordinary schools (Table 7). The selected out sample had very significantly slower $(\mathrm{P}<0.005)$ hand speeds than both the controls and the selected in sample.

Intelligence. The selected in sample had a significantly higher intelligence $(\mathrm{P}<0 \cdot 0025)$ than both the selected out sample and the unselected cohort $(P<0.005)$. The latter two samples had very similar full scale intelligence quotients (IQ), just above the upper limit of educational subnormality, while the selected in sample had a mean score within the low average range of intelligence (Table 8).

Dividing the IQ scores of the three samples into conventional categories shows that the unselected and selected out subjects were very similar, especially at the extremes of the range, and just under half of both groups have an IQ within the intellectually competitive range ( 80 or more) (Table 9 ). Three

Table 7 Hand speed (seconds) on the test of motor impairment among selectively treated spina bifida cases and matched controls (values, mean (SD))

\begin{tabular}{llll}
\hline Patient groups & $\begin{array}{l}\text { Peg board } \\
\text { right hand }\end{array}$ & $\begin{array}{l}\text { Peg board } \\
\text { left hand }\end{array}$ & $\begin{array}{l}\text { Simultaneous } \\
\text { counters }\end{array}$ \\
\hline Selected in $(\mathrm{n}=44)$ & $32 \cdot 1(15 \cdot 9)$ & $31 \cdot 8(18 \cdot 6)$ & $17 \cdot 2(7 \cdot 1)$ \\
Selected out $(\mathrm{n}=14)$ & $75 \cdot 5(39 \cdot 7)$ & $60 \cdot 4(28 \cdot 1)$ & $36 \cdot 2(21 \cdot 3)$ \\
Controls $(\mathrm{n}=56)$ & $21 \cdot 0(7 \cdot 4)$ & $24 \cdot 6(11 \cdot 0)$ & $14 \cdot 5(5 \cdot 2)$ \\
\hline
\end{tabular}

Table 8 Measurement of intelligence in the three patient groups (values, mean (SD))

\begin{tabular}{llll}
\hline & Verbal IQ & $\begin{array}{l}\text { Performance } \\
I Q\end{array}$ & Full scale IQ \\
\hline Unselected $(\mathrm{n}=39)$ & $81 \cdot 4(20 \cdot 6)$ & $74 \cdot 2(20 \cdot 6)$ & $75 \cdot 7(22 \cdot 4)$ \\
Selected in $(\mathrm{n}=49)$ & $94 \cdot 3(16 \cdot 7)^{*}$ & $91 \cdot 3(17 \cdot 2)^{*}$ & $88 \cdot 0(22 \cdot 2)$ \\
Selected out $(\mathrm{n}=16)$ & $82 \cdot 2(17 \cdot 8)$ & $64 \cdot 5(15 \cdot 3)^{\dagger}$ & $73 \cdot 3(22 \cdot 9)$ \\
\hline${ }^{*} \mathrm{n}=42 ; \mathrm{n}=11$. & & &
\end{tabular}

Table 9 Distribution of intelligence in the three patient groups

\begin{tabular}{lrrrl}
\hline Patient group & $100+$ & $80-99$ & $50-79$ & $<49$ \\
& No $(\%)$ & No $(\%)$ & No $(\%)$ & No $(\%)$ \\
\hline Unselected $(\mathrm{n}=39)$ & $6(15)$ & $12(31)$ & $15(38)$ & $6(15)$ \\
Selected in $(\mathrm{n}=49)$ & $16(33)$ & $18(37)$ & $12(24)$ & $3(6)$ \\
Selected out $(\mathrm{n}=16)$ & $3(19)$ & $4(25)$ & $7(44)$ & $2(13)$ \\
\hline
\end{tabular}

children not submitted for immediate surgery but with shunted hydrocephalus seem to have fairly good prospects, with IQ above 100. A third of the selected in subjects, however, also have IQ above 100 and their incidence of severe mental retardation is just under half that of the other samples. One of the three severely mentally retarded children had hydrocephalus treated with a shunt, but the other two had an encephalocele. If patients with encephalocele are excluded, the IQ of the selected in group rises to mean (SD), $90.6(18.9)$ and a similar exclusion among the unselected group increases their overall IQ by just two points to $78 \cdot 6(20 \cdot 2)$. None of the children with meningocele in either the unselected or selected in series showed evidence of mental retardation.

\section{Discussion}

The management of spina bifida cystica has changed over the past two decades. In the 1960s there was an enthusiasm for early surgical closure of the back lesion followed by prompt insertion of a ventriculoatrial shunt for control of the associated hydrocephalus. Aggressive management of deformities and infections was then undertaken requiring numerous operations and hospital admissions. ${ }^{10}$ In the 1970s, a decade of this management showed a large number of severely disabled youngsters and prompted a review of the wisdom of this treatment. A number of articles were published, beginning with that of Lorber,' indicating the advantages of selection for treatment. Major adverse criteria definable at birth have been studied, most requiring no special investigations and relating to easily recognised physical signs. These criteria relate, in the main, to predictable physical handicaps, although Shurtleff $e t$ 
$a l^{11}$ recommended aggressive treatment of the lesion in the presence of good intellectual prognosis, based on an estimate of brain mass and the absence of infection in the nervous system. The estimate of brain mass, however, required invasive techniques to obtain the necessary information, but was an attempt to select children for surgery based upon intellectual prognosis rather than predominantly physical criteria.

It is evident that there are differing survival rates and the quality of survival varies from unit to unit. ${ }^{211-13}$ A source of concern among those caring for these children has been the proportion of survivors among the group not receiving immediate surgery to the back lesion. It is apparent from the figures that the criteria being applied for selection are not criteria relating to mortality but rather to morbidity, whether they be primarily physical or intellectual. The criteria for selection applied in our own unit are very similar to those universally accepted and are based on Lorber's recommendations. We have been reluctant to exclude from surgery on the basis of paraplegia alone, and in the absence of other adverse criteria. We have found that parents of the babies selected out for immediate surgery often request that they have the child home and it has been our practice to allow them to care for their child if they so wish, provided that we feel they can manage the care of the unoperated lesion. This policy has resulted in a number of survivors being presented for further treatment after healing of the back lesion. Parents are anxious that the hydrocephalus be effectively treated and we have responded promptly to their request that the child be included in a treatment programme. Valve insertion rates and the time of insertion of the first shunt has thus been very similar in the selected in and selected out groups.

This study suggests that children selected for initial closure of their back lesion have better mobility at 5 to 7 years of age than those in the selected out group, as would be expected from the use of the neurological level of the spinal lesion as one of the adverse criteria. It is evident also that they have better mobility compared with the unselected group. Among those selected in, just over one third have urinary continence and normal urinary tracts.

When all the survivors are considered in this study it is clear that selection does not decrease the need for shunt treatment of the hydrocephalus. Mobility, continence, and intelligence, however, are improved in the selected in group, but not in those excluded from initial treatment. The particular group designated selected out in this study have proved of considerable interest in the light of anxiety expressed regarding the long term effects of delaying treatment in patients surviving, after an initial decision not to operate on the back. Survivors in this group are more physically handicapped than the other groups, invariably requiring wheelchairs for mobility, and are all incontinent of urine and faeces. They also have appreciably poorer hand function. Although a much higher proportion have valve dependant hydrocephalus than the unselected subjects, the overall IQ are very similar with approximately equal numbers having above average scores. Withdrawing or delaying surgery to the back lesion does not necessarily increase their risk of mental handicap assuming that the hydrocephalus is promptly and effectively treated.

We thank Action Research-The National Fund for Research into Crippling Disease for their generous financial support: Gill Beasley for coordinating the study; Sarah MacMahon for data preparation and Valerie McBroom for computer programming: the children, parents, and teachers for their ready cooperation.

\section{References}

' Lorber J. Results of treatment of myelomeningocele. An analysis of 524 unselected cases with special reference to possible selection for treatment. Dev Med Child Neurol 1971:13:279-303.

2 Lorber J. Salfield SAW. Results of selective treatment of spina bifida cystica. Arch Dis Child 1981:50:822-30.

${ }^{3}$ Sklayne K. Factors governing the school placement of children with spina bifida and hydrocephalus (Thesis). Manchester: University of Manchester, 1982.

${ }^{4}$ Weatherall JAC. A review of some effects of recent medical practices in reducing the numbers of children born with congenital abnormalities. Health Trends 1982;14:86-8.

5 Anonymous. Spina bifida and anencephaly: fewer patients, more problems [Editorial]. Br Med J 1983:286:1679-80.

- Tew B. Educational, social and psychological consequences of spina bifida cystica and its complications. In: Palmer J, ed. Special education and the new community services. Ferndale, Glamorgan: Ron Jones Publications, 1973.

7 Tew B, Laurence KM. The effects of hydrocephalus on intelligence, visual perception and school attainments. Dev Med Child Neurol 1975;35(Suppl):129-35.

${ }^{8}$ Man DWK. Forest DM. The prognosis of occipital encephalocele. Experience of 46 cases. Z Kinderchir 1982;37:158-60.

${ }^{9}$ Blaauw G. Hydrocephalus and epilepsy. Z Kinderchir 1978;25: 341-5.

${ }^{10}$ Tew B, Laurence KM. The effects of admission to hospital and surgery on children with spina bifida and hydrocephalus. Dev Med Child Neurol 1976;18(Suppl 37):119-25.

"Shurtleff DB, Hayden PW, Loesser JD, Kronmal RA. Myelodysplasia, decision for death or disability. $N$ Engl J Med 1974;291:1005-11.

12 Guincy EJ. MacCarthy P. Implications of a selective policy in the management of spina bifida. J Pediatr Surg 1981;16:136-8.

${ }^{13}$ Gross RH. Cox A. Tatyrek R, Pollay M, Barnes WA. Early management and decision making for the treatment of myclomeningocele. Pediatrics 1983:72:450-8.

Correspondence to Dr R C Evans, Department of Child Health, University of Wales College of Medicine. Heath Park, Cardiff CF4 $4 \times N$.

Received 16 November 1984 